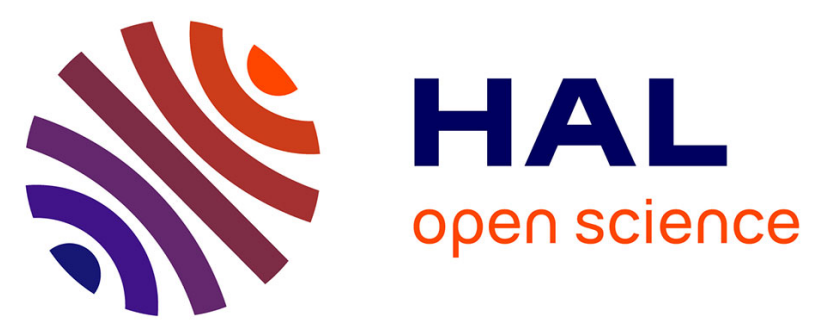

\title{
Structural and spectroscopic investigations of nine-coordinate redox active lanthanide complexes with a pincer $\mathrm{O}, \mathrm{N}, \mathrm{O}$ ligand
}

D. Mouchel Dit Leguerrier, R. Barré, M. Bryden, D. Imbert, C. Philouze, O. Jarjayes, D. Luneau, .J. K. Molloy, F. Thomas

\section{To cite this version:}

D. Mouchel Dit Leguerrier, R. Barré, M. Bryden, D. Imbert, C. Philouze, et al.. Structural and spectroscopic investigations of nine-coordinate redox active lanthanide complexes with a pincer O,N,O ligand. Dalton Transactions, 2020, 49 (24), pp.8238-8246. 10.1039/d0dt01388a . hal-02916328

\section{HAL Id: hal-02916328 \\ https://hal.science/hal-02916328}

Submitted on 12 Oct 2021

HAL is a multi-disciplinary open access archive for the deposit and dissemination of scientific research documents, whether they are published or not. The documents may come from teaching and research institutions in France or abroad, or from public or private research centers.
L'archive ouverte pluridisciplinaire HAL, est destinée au dépôt et à la diffusion de documents scientifiques de niveau recherche, publiés ou non, émanant des établissements d'enseignement et de recherche français ou étrangers, des laboratoires publics ou privés. 


\section{Journal Name}

\section{ARTICLE}

Received 00th January 20xx, Accepted 00th January 20xx

DOI: $10.1039 / \times 0 x \times 00000 x$

www.rsc.org/

\section{Structural and spectroscopic investigations of nine-coordinate redox active lanthanide complexes with a pincer $\mathrm{O}, \mathrm{N}, \mathrm{O}$ ligand}

D. Mouchel Dit Leguerrier, ${ }^{\text {a }}$ R. Barré, ${ }^{a}$ M. Bryden, ${ }^{a}$ D. Imbert, ${ }^{b}$ C. Philouze, ${ }^{a}$ O. Jarjayes, ${ }^{,}$D. Luneau, ${ }^{c}$ J. K. Molloy, ${ }^{\mathrm{a}^{*}}$ F. Thomas ${ }^{\mathrm{a}^{*}}$

The lanthanide complexes $\mathbf{E u L}_{3}, \mathrm{GdL}_{3}, \mathrm{YbL}_{3}$ and $\mathbf{L u L}_{3}$ of the $\mathrm{N}, \mathrm{N}^{\prime}$-bis(2-hydroxy-di-3,5-tert-butylphenyl)amine were prepared. The X-Ray crystal structures of $\mathrm{GdL}_{3}$ and $\mathbf{L u L}_{3}$ demonstrated a nine-coordinate sphere with three ligand molecules under their anionic diamagnetic form (Cat- $\mathrm{N}-\mathrm{BQ})$. The complexes showed three oxidation events $\left(\mathrm{E}_{1 / 2}{ }^{0 \times 1}=0.15\right.$ $0.16{\mathrm{~V}, \mathrm{E}_{1 / 2}}^{2}=0.51-55 \mathrm{~V}$, and $\mathrm{E}_{1 / 2}{ }^{3}=0.75-0.78 \mathrm{~V} \mathrm{vs} \mathrm{Fc} / \mathrm{Fc}$ ) via cyclic voltammetry, corresponding to the successive oxidation of the catecholate moeities to iminosemiquinone species. The complexes $\mathrm{GdL}_{3}$ and $\mathrm{YbL}_{3}$ were characterized by EPR spectroscopy, allowing for the determination of the zero field splitting (ZFS) parameters in the first case. The monocations $\left(\mathrm{LnL}_{3}\right)^{+}$and monoanions $\left(\mathrm{LnL}_{3}\right)^{-}$were electrochemically generated $\left(\mathrm{Ln}=\mathrm{Eu}, \mathrm{Gd}, \mathrm{Yb}\right.$, Lu), as well as the dications $\mathrm{YbL}_{3}{ }^{2+}$ and $\mathrm{LuL}_{3}{ }_{3}^{+}$. The spins are anti-ferromagnetically exchange coupled in the diradical species $\mathrm{LuL}_{3}{ }^{2+}(|\mathrm{D}|=260 \mathrm{MHz}, \mathrm{E}=0)$. All the complexes (incl. neutral) possess a strong absorption band in the NIR region $\left(730-840 \mathrm{~nm}, \varepsilon>28 \mathrm{mM}^{-1} \mathrm{~cm}^{-1}\right)$ corresponding to ligand-based transitions.

\section{Introduction}

The coordination chemistry of redox-active ligands currently attracts a considerable interest. ${ }^{1-11}$ It was boosted by the discovery of metal-radical entities in the active site of several enzymes in the early 90 's. ${ }^{12-18}$ A great number of biomimetic radical complexes were described, especially of galactose oxidase, ${ }^{19}$ followed by impressive catalytic applications, most particularly in organometallic chemistry. ${ }^{1,4}$, $20-25$ Very recently a new approach, which combines redox-active ligands and lanthanide ions has emerged in the literature, with downstream applications in detection and imaging of oxidative stress. ${ }^{26-35}$ Lanthanide complexes have been long developed for medical imaging due to their fascinating optical and magnetic properties. $1^{36}$ They have been hitherto rarely used as redox probes due to their strong stability in the +III state (except europium). Their association with pro-radical ligands, capable of reversibly shuttling between two oxidation states, was recently proved to confer on them a unique redox character, expending now their potential towards redox probes. $^{37-39}$

We have recently reported a series of lanthanides complexes involving sterically hindered phenolate moieties. ${ }^{37-39}$ We

a. Univ. Grenoble Alpes, CNRS, DCM, 38000 Grenoble, France.

b. Univ. Grenoble Alpes, CEA, CNRS, IRIG-LCBM, 38000 Grenoble, France. c. LMI, Université Claude Bernard Lyon 1, France.

+ Footnotes relating to the title and/or authors should appear here.

Electronic Supplementary Information (ESI) available: [details of any supplementary information available should be included here]. See
DOI: $10.1039 / \times 0 \times 00000 \times$ demonstrated that the ligand can undergo successive ligand-based oxidations affording phenoxyl radicals, which manifests in a decrease in lanthanide-centered luminescence. The stability of the phenoxyl radicals was however not sufficient to envisage biological applications in spite of the presence of electron donating tert-butyl and/or methoxy substituents. In addition the phenolate oxidation potentials in these complexes are in general higher than in related d-transition metal complexes due to the tripositive charge of the lanthanides and the ionicity of the coordination bonds. In order to overcome these two limitations we extended our investigations to aminophenol derivatives. This substitution pattern is known to decrease the oxidation potential to such an extent that the ligand usually undergoes air oxidation once deprotonated and engaged in coordination with $1^{\text {st }}$ row metal centers. ${ }^{40-44}$

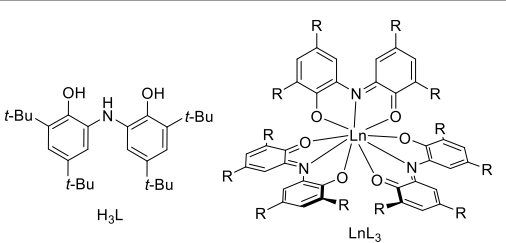

Figure 1. Structure of $\mathrm{H}_{3} \mathrm{~L}$ and the neutral lanthanide complexes $(\mathrm{Ln}=\mathrm{Eu}, \mathrm{Gd}, \mathrm{Yb}$
$\mathrm{Lu}$. $\mathrm{R}=t-\mathrm{Bu}$ in the structure of the complex.

Herein we investigated the coordination chemistry with lanthanide ions of the pincer ligand $\mathrm{H}_{3} \mathrm{~L}$, whose redox noninnocence has been established some decades ago (Figure 1) ${ }^{45-55}$. This ligand architecture has been chosen because it provides a hard 
$\mathrm{N}_{2} \mathrm{O}$ donor set ideal for lanthanide ions. Furthermore the typical high coordination number of lanthanide ions can be readily assessed by controlling the metal:ligand ratio during the synthesis. ${ }^{56}$ Hence, nine-coordinate lanthanide complexes $(\mathrm{Ln}=\mathrm{Eu}, \mathrm{Gd}, \mathrm{Yb}$, Lu) with 1:3 (Ln:L) ratios were isolated. Each ligand adopts the (Cat-N-BQ) oxidation state (Figure 1, Scheme 1). Three oxidation processes are observed, assigned to the successive oxidation of the (Cat-N-BQ) moieties to SQ-N-BQ radicals. The first reduction event leads to a mono radical species comprising the (Cat-N-SQ $)^{2-}$ moiety. All the complexes exhibit strong absorption bands in the NIR region.

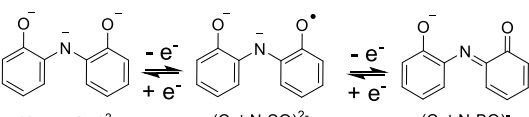

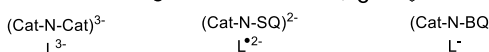

$$
\begin{aligned}
& e^{-1}-e^{-} \\
& \text {i) } \\
& \text { (SQ-N-BQ) }
\end{aligned}
$$

\section{Results and discussion}

\subsection{Synthesis}

The complexes $\mathbf{L n L}_{\mathbf{3}}$ were synthesised using a directed synthesis with tert-butyl catechol, ammonia and the corresponding metal nitrate salt (Eu', $\left.\mathrm{Gd}^{\prime \prime \prime}, \mathrm{Yb}^{\prime \prime \prime}, \mathrm{Lu}^{\prime \prime \prime}\right)$ to afford a dark blue solid. ${ }^{56}$ The synthesis of $\mathrm{LnL}_{3}$ was also carried out by complexation of the lanthanide salt with three molar equivalents of the ligand $\mathrm{H}_{3} \mathrm{~L},{ }^{45,46}$ but templation was faster and resulted in higher yields.

\subsection{Structures of the complexes}

The four complexes were crystallized by slow evaporation of a dichloromethane solution. Unfortunately only the crystals of $\mathbf{G d L}_{3}$ and $\mathbf{L u L}_{3}$ were of an acceptable quality for structure determination by X-Ray diffraction despite many efforts to improve the crystallization conditions. Hence complexes $\mathbf{L n L}_{3}$ ( $\mathrm{Ln}=\mathrm{Gd}, \mathrm{Lu}$ ) are found to be isostructural and the absence of any counter-ion in the crystal cell evidences that each ligand coordinates under its closed-shell monoanionic form $\mathbf{L}^{-}$ (Scheme 1, 2). In other terms, the ligand has been oxidized by air during the synthetic process to finally adopt the iminoquinone-aminophenolate form (Cat-N-BQ) $\left(\mathbf{L}^{-}\right) .^{57}$ These complexes demonstrate each a nine-coordinate lanthanide ion, similarly to the lanthanum, samarium and strontium complexes, which were previously reported. ${ }^{58-60}$ It was assumed that compounds with ( $\mathrm{Eu}^{\mathrm{III}}$ and $\mathrm{Yb}^{\mathrm{III}}$ ) demonstrated the same structure and were analysed accordingly.
The coordination environment is best described as tricapped trigonal prism (Figure 2, Table S1) in both $\mathbf{G d L}_{3}$ and $\mathbf{L u L}_{3} .{ }^{61}$ The lanthanide ion is coordinated by one nitrogen and two oxygen atoms of the three ligands $\mathrm{L}^{-}$. The $\mathrm{Ln}-\mathrm{N}$ bond distances ranges are $2.555-2.578(4) \AA\left(\mathrm{GdL}_{3}\right)$ and $2.50-2.52(1) \AA\left(\mathrm{LuL}_{3}\right)$. The slight shortening of the $\mathrm{Ln}-\mathrm{N}$ bonds with the changing size of the lanthanides follows the trend of the lanthanide contraction. It is worth noting that the tert-butyl groups shield the metal ion and thus preclude further incorporation of solvent molecule in the coordination sphere. (a)

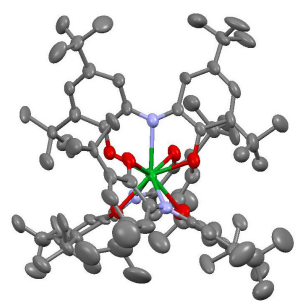

(b)

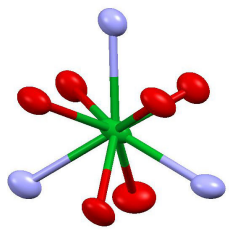

Figure 2. Structure of (a) LuL (the hydrogen atoms are omitted for clarity) and
(b) the coordination polyhedron within LuL

\subsection{Electrochemistry}

The complexes $\mathrm{LnL}_{3}$ were each investigated for their redox activity in $\mathrm{CH}_{2} \mathrm{Cl}_{2}$ solution using cyclic voltammetry (CV), differential pulse voltammetry (DPV), and rotating disk electrode (RDE) voltammetry.

The CV curve of $\mathrm{LuL}_{3}$ is shown in Figure 3, while the others are depicted in ESI. The complexes $\mathbf{E u L}_{3}, \mathbf{G d L}_{3}, \mathbf{Y b L}_{3}$ and $\mathbf{L u L}_{3}$ demonstrated similar oxidation behaviour with three redox processes at $E_{1 / 2}{ }^{o \times 1}=0.16 \mathrm{~V}, E_{1 / 2}{ }^{\text {ox2 }}=0.51-55 \mathrm{~V}$, and $E_{1 / 2}{ }^{o \times 3}=$ $0.75-0.78 \mathrm{~V}$ vs $\mathrm{Fc}^{+} / \mathrm{Fc}$. The complexes of the smallest lanthanides exhibit the highest oxidation potentials, presumably due to the close proximity between the positively charged metal and the redox-active phenolate moieties. Each of these oxidation events corresponds to a one-electron oxidation, as confirmed by rotating disk electrode. They are assigned to the successive oxidations of the aminophenolate moieties to iminosemiquinone radicals. ${ }^{45-49,51-54}$ At $298 \mathrm{~K}$ the first oxidation process is reversible for all four complexes, attesting that the stability of the monocation is noteworthy. The second oxidation wave is reversible at $298 \mathrm{~K}$ for $\mathrm{YbL}_{3}$ and $\mathbf{L u L}_{3}$, but not for $\mathrm{EuL}_{\mathbf{3}}$ and $\mathbf{G d L}_{\mathbf{3}}$. The reversibility is restored upon decreasing the temperature to $233 \mathrm{~K}$ for these latter complexes, showing that the nature of the lanthanide significantly affects the stability of the diradical species. Hence the dications $\mathbf{L n L}_{3}{ }^{2+}$ of the smaller lanthanides are the most stable ones based on the reversibility of the CV. Finally it must be emphasized that the shifts in potentials observed upon decreasing the temperature do not exceed that predicted by the Nernst law. Hence, ion-pairing effects with perchlorate ions from TBAP electrolyte are negligible in the present series, in contrast with previously found for lanthanide complexes of tripodal tris(salicylidene) ligands. ${ }^{38,39}$ 


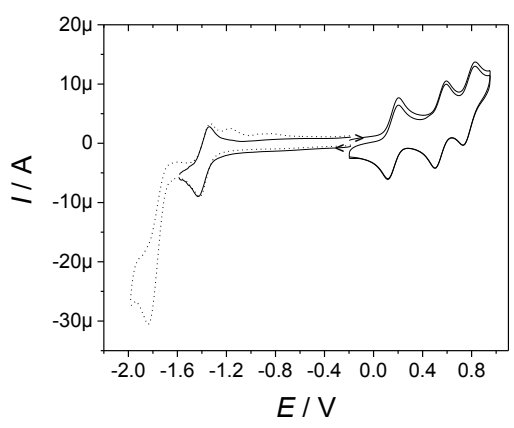
Figure 3. Cyclic voltammetry curve of a $0.5 \mathrm{mM} \mathrm{CH}_{2} \mathrm{Cl}_{2}$ solution (containing $0.1 \mathrm{M}$
TBAP as supporting electrolyte) of $\mathrm{LuL}_{3}$ at a carbon electrode. The potentials are
referenced vs. the $\mathrm{Fc}^{\prime} / \mathrm{Fc}^{\mathrm{F}}$ redox couple. $T=298 \mathrm{~K}$, scan rate $=0.1 \mathrm{~V} / \mathrm{sec}$.

The electrochemical behaviour of the four neutral complexes has been also investigated in reduction. They all display a reversible monoelectronic reduction wave in the range -1.33 to $-1.39 \mathrm{~V}$. The similarity in reduction potentials within the series argues for redox processes of identical nature, which is assigned to the reduction of one $\mathrm{L}^{-}$ligand molecule to an iminosemiquinone radical $\mathrm{L}^{2-}$ (Figure 2). ${ }^{45,48,49,51-53}$ Additional reduction waves are observed but these are irreversible, indicative of coupled chemical reactions. Due to the irreversibility they have not been further investigated.

\begin{tabular}{ccccc}
\hline \multicolumn{5}{c}{ Table 1. Electrochemical data of the complexes } \\
\hline Complex & $\mathrm{E}_{1 / 2}{ }^{1}(\Delta \mathrm{E})$ & $\mathrm{E}_{1 / 2}{ }^{\circ \times 1}(\Delta \mathrm{E})$ & $\mathrm{E}_{1 / 2}{ }^{\mathrm{ox}}(\Delta \mathrm{E})$ & $\mathrm{E}_{1 / 2}{ }^{\mathrm{ox}}(\Delta \mathrm{E})$ \\
$\mathrm{EuL}_{3}$ & $-1.33(0.09)$ & $0.16(0.08)$ & $0.51(0.09)^{[b]}$ & $0.75(0.10)^{[b]}$ \\
$\mathrm{GdL}_{3}$ & $-1.33(0.09)$ & $0.16(0.08)$ & $0.53^{[\mathrm{b}]}$ & $0.76^{[\mathrm{b}]}$ \\
$\mathrm{YbL}_{3}$ & $-1.38(0.09)$ & $0.16(0.08)$ & $0.54(0.09)$ & $0.78(0.11)$ \\
$\mathrm{LuL}_{3}$ & $-1.39(0.09)$ & $0.16(0.09)$ & $0.55(0.09)$ & $0.78(0.10)$
\end{tabular}

[a] In $0.5 \mathrm{mM} \mathrm{CH}_{2} \mathrm{Cl}_{2}$ solutions containing TBAP as supporting electrolyte. All the potentials values are given in $\mathrm{V}$ and referred to the $\mathrm{Fc}^{+} / \mathrm{Fc}$ redox couple. $T=298$ $\mathrm{K}$; scan rate, $0.1 \mathrm{~V} / \mathrm{sec}$. Parameters for the ferrocene against the reference used $\left(\mathrm{AgNO}_{3} 0.01 \mathrm{M}\right): \mathrm{E}_{1 / 2}=0.185 \mathrm{~V}(\Delta \mathrm{E}=0.08)$

${ }^{[b]}$ Irreversible at $298 \mathrm{~K}$. The $\mathrm{E}_{1 / 2}{ }^{0 \times 2}$ and $\mathrm{E}_{1 / 2}{ }^{0 \times 3}$ values are calculated from the DPV curve by adding half of the pulse amplitude to the peak potential.

\subsection{Vis-NIR properties of the complexes}

The Vis-NIR spectra of the neutral lanthanide complexes $\mathbf{~} \mathbf{L L}_{3}$ are very similar (Figure 4 and ESI) and display a characteristic twin band at 742-757 $\mathrm{nm}\left(\varepsilon \sim 38-42 \mathrm{mM}^{-1} \mathrm{~cm}^{-1}\right)$ and 818-824 $\mathrm{nm}\left(\varepsilon \sim 35-40 \mathrm{mM}^{-1} \mathrm{~cm}^{-1}\right)$, together with a band in the range $442-450 \mathrm{~nm}\left(\varepsilon \sim 8.6-9.9 \mathrm{mM}^{-1} \mathrm{~cm}^{-1}\right)$. These bands are assigned to quinone based transitions on the basis of similarities with the oxidized free (Cat-N-BO) K ligand ${ }^{54}$ and previously reported $d$ - and f-metal complexes of the same ligand. ${ }^{51,53}$ Their presence corroborates air oxidation of the in situ formed ligand into (Cat- $\mathrm{N}-\mathrm{BQ})^{-}$during complexation.

The cations $\mathrm{LnL}_{3}{ }^{+}, \mathrm{LnL}_{3}{ }^{2+}$ and anions $\mathrm{LnL}_{3}{ }^{-}(\mathrm{Ln}=\mathrm{Gd}, \mathrm{Eu}, \mathrm{Yb}, \mathrm{Lu})$ were generated electrochemically. Upon one-electron oxidation the shape of the NIR feature evolves significantly (black to red line, Figure 4), giving a triple band with maxima at ca. 684-704 $\mathrm{nm}\left(\varepsilon \sim 28-43 \mathrm{mM}^{-1} \mathrm{~cm}^{-1}\right), 748-768 \mathrm{~nm}(\varepsilon \sim 28-42$ $\left.\mathrm{mM}^{-1} \mathrm{~cm}^{-1}\right)$ and $818-836 \mathrm{~nm}\left(\varepsilon \sim 29-44 \mathrm{mM}^{-1} \mathrm{~cm}^{-1}\right)$. Sharp bands are additionally detected at 460-466 nm $(\varepsilon \sim 14-20 \mathrm{mM}$ ${ }^{1} \mathrm{~cm}^{-1}$ ), where the semiquinone transitions are usually found, disclosing oxidation of one (Cat-N-BQ) moieties into radical (SQ-N-BQ). The two-electron oxidation was limited to $\mathrm{YbL}_{3}$ and $\mathrm{LuL}_{3}$, e.g. the complexes that show the greatest reversibility of the second redox wave in their CV. For both complexes the current decreases continuously during electrolysis, giving a current lower than $5 \%$ of the initial one after theoretical removal of about 1.6 electrons, time at which electrolysis was stopped. By rotating disc electrode (RDE) voltammetry the ratio dication:monocation was confirmed to be $56: 44$ and 59:41 at the end of electrolysis for $\mathrm{YbL}_{3}{ }^{2+}$ and $\mathrm{LuL}_{3}{ }^{2+}$ respectively. We tentatively interpret this behaviour by the formation of passivating ion pairs, which prevent full electrolysis. It is further supported by a significant decrease in the intensities of the plateaux of the RDE in the case of $\mathrm{YbL}_{3}{ }^{2+}$. The electrolytic solution after electrolysis shows the triple NIR band evidenced in the cations, with a somewhat weaker intensity (Table 2), while a new intense feature is observed at $370 \mathrm{~nm}$ (ratio of absorbance at 370 over $680 \mathrm{~nm}$ larger than 1) where phenolate/phenoxyl transitions are expected to be found (blue line, Figure 4). This behaviour is consistent with two successive ligand-centered oxidations which afford the bis(SQ-N-BQ) radical species.

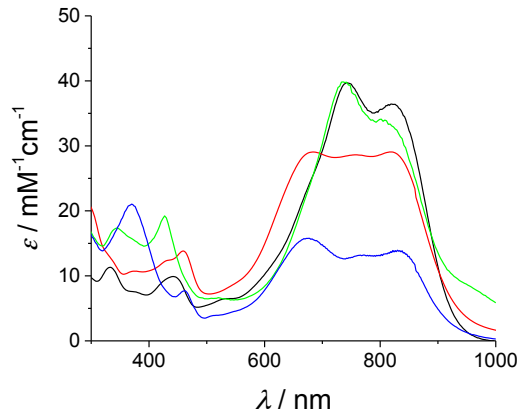

Figure 4. UV-Vis-NIR spectra of $0.5 \mathrm{mM} \mathrm{CH} \mathrm{Cl}_{2}$ solutions (containing $0.1 \mathrm{M}$ TBAP

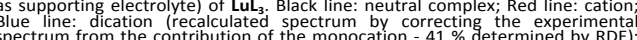
spectrum from the contribution of the monocation $-41 \%$ determined by RDE);

Interestingly the electrochemically generated dications $\mathrm{YbL}_{3}{ }^{2+}$ and $\mathrm{LuL}_{3}{ }^{2+}$ were stable at the hour timescale at $233 \mathrm{~K}$, but decompose rapidly at r.t. (within the minute timescale for 
$\left.\mathrm{LuL}_{3}{ }^{2+}\right)$. The decomposition path affords primarily the monocation, which further evolves towards the neutral precursor within one hour range.

The electrochemical reduction of the neutral complexes is accompanied by changes in the intensity of the bands in the 730-850 nm region, as well as the appearance of a NIR shoulder (at $950 \mathrm{~nm}$, green line in Figure 4). These modifications are accompanied by the appearance of a sharp band at $410 \mathrm{~nm}$, which is reminiscent of phenoxyl radical species. ${ }^{53}$ It is worth noting that similar spectra were obtained for $\mathrm{EuL}_{3}{ }^{-}$and the other anions. Furthermore a similar spectral evolution was reported for the one-electron reduction of the related bis(aminophenolate)zinc complex. ${ }^{51}$ This supports a ligand-centered reduction processes for all the complexes. In other terms the europium ion, which is the only one prone to reduction, ${ }^{62}$ retains its (+III) oxidation state in the anion. Hence the anion forms via reduction of one ligand molecule to $(\text { Cat- } \mathrm{N}-\mathrm{SQ})^{2-}\left(\mathrm{L}^{-2-}\right)$ (Figure 1 ). Not surprisingly the one-electron reduced products are sensitive to oxygen. In every case the exposure to air of a $\mathrm{CH}_{2} \mathrm{Cl}_{2}$ solution of $\mathrm{LnL}_{3}{ }^{-}$results in the recovery of the spectrum of $\mathrm{LnL}_{3}$.

\subsection{Photophysical properties of the complexes}

The lanthanide ions Eu"' and $\mathrm{Yb}^{\text {III' }}$ are classical visible and NIR emitters, respectively. In our case the emission spectra of $\mathrm{EuL}_{3}$ and $\mathrm{YbL}_{3}$ (both at r.t. and $200 \mathrm{~K}$ ) however do not show any metal-centered luminescence. The strong ligand-centered absorption bands in the Vis and NIR regions likely preclude the population of the excited state of the lanthanide ions. Consequently the luminescence of both the $\mathrm{Eu}^{\text {III }}$ and $\mathrm{Yb}^{\mathrm{III}}$ ion is efficiently quenched due to reabsorption. The same behaviour was observed for the corresponding cations and dications.

\section{Table 2. Vis-NIR data of the complexes ${ }^{[a]}$}

\section{Complex $\quad \lambda / \varepsilon\left(\mathrm{nm} / \mathrm{mM}^{-1} \mathrm{~cm}^{-1}\right)$}

$\mathrm{EuL}_{3} \quad 336(11.23), 450(8.570), 757$ (39.73), 824 (37.83)

[EuL $]^{+} \quad 466(14.10), 688(27.95), 748(29.06), 836(30.14)$

[EuL $\left.L_{3}\right] \quad 342(15.09), 428(14.04), 750(40.18), 816(38.69)$

GdL $_{3} \quad 336(10.99), 448(8.680), 752(42.31), 825$ (39.88)

[GdL $\left._{3}\right]^{+} \quad 466(19.72), 704(43.04), 754(42.18), 836(43.66)$

[GdL $\left.]_{3}\right]^{\circ} \quad 343(11.75), 430(11.43), 751(37.65), 817(35.28)$

$\mathrm{YbL}_{3} \quad 335(10.20), 447(9.160), 747(37.26), 818(35.06)$

[YbL $\left._{3}\right]^{+} \quad 460(15.28), 688(33.68), 768(32.34), 828(33.63)$

[ $\left.\mathrm{YbL}_{3}\right]^{-} \quad 340(13.39), 428(13.77), 742(36.12), 816(31.70)$

$\mathrm{LuL}_{3} \quad 334(11.32), 442(9.900), 742(39.74), 820$ (36.43)

$\left[\mathrm{LuL}_{3}\right]^{+} \quad 460(13.82), 684(29.05), 756(28.63), 818(29.07)$

$\left[\mathrm{LuL}_{3}\right]^{2+b \mathrm{~b}]} \quad 370(21.04), 462(7.720), 676(15.78), 830(13.95)$

[LuL L $_{3} \quad 346(17.36), 427$ (19.22), 736 (39.84), 802 (34.11)

[a] In $0.5 \mathrm{mM} \mathrm{CH}_{2} \mathrm{Cl}_{2}$ solutions containing TBAP as supporting electrolyte (0.1 M). The cations and monocations were electrochemically generated. All the potentials values are given in $\mathrm{V}$ and referred to the $\mathrm{Fc} / \mathrm{Fc}$ redox couple. $T=298$ $\mathrm{K}$; scan rate, $0.1 \mathrm{~V} / \mathrm{sec}$

${ }^{[b]}$ From spectral deconvolution. For the dication $\left[\mathrm{YbL}_{3}\right]^{2+}$ the height of the plateaux of the RDE was significantly lower than for the monocation. This suggests loss of material (possibly by precipitation onto the electrode surface) precluding spectral deconvolution and determination of molar extinction coefficients.

\subsection{Magnetic susceptibility}

The temperature dependence of the product of the molar magnetic susceptibility of the neutral complexes $\mathbf{E u L}_{3}, \mathbf{G d L}_{3}$ and $\mathbf{Y b L}_{3}$ is presented in the form of the $\chi \mathrm{T}$ product, as shown in Figure 5.

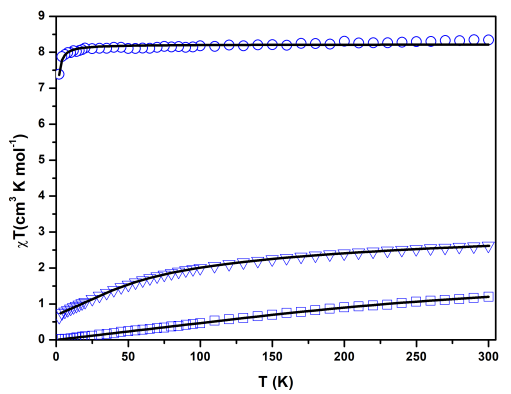

Figure 5: Experimental $\chi \mathrm{T}$ vs. T plots for EuL (bottom), Yb $_{3}$ (middle) and GdL
(top) with solid lines for best fit with PHI software (see text). For $\mathrm{EuL}_{3}$ the $\chi \mathrm{T}$ is $1.20 \mathrm{emu} \mathrm{K} \mathrm{mol}{ }^{-1}$ at $300 \mathrm{~K}$ then decreases continuously upon cooling to zero at $2 \mathrm{~K}$ as is expected for such an $\mathrm{Eu}^{3+}$ complex (Figure 5). ${ }^{64,65}$ This comes from the thermal depopulation of the exited states issued of the splitting of the ${ }^{7} \mathrm{~F}_{0 \rightarrow>6}$ ground term by the spin-orbit coupling. ${ }^{66}$ Accordingly the magnetic susceptibility of EuL $_{3}$ is well fitted (Figure 5) with a spin-orbit coupling parameter $\lambda$ of $237( \pm 1)$ $\mathrm{cm}^{-1}$ which compares well with others. ${ }^{64,65,67}$

For $\mathrm{YbL}_{3}$ the $\chi^{\top}$ value is $2.62 \mathrm{emu} \mathrm{K} \mathrm{mol}^{-1}$ at $300 \mathrm{~K}$ then decreases continuously upon cooling to reach $0.64 \mathrm{emu} \mathrm{K} \mathrm{mol}^{-}$ 1 at $2 \mathrm{~K}$ (Figure 5). As well for the magnetization, it is continuously increasing with the magnetic field to reach 1.45 $\mu_{B}$ at 5T. These values and behavior are in agreement with previous works. ${ }^{62,68,69}$ For a better description, the magnetic susceptibility data have been fitted ${ }^{63}$ (Figure 5) with Crystal Field Parameters $B_{2}^{0}, B_{4}^{0}$ and $B_{6}^{0}$ in Steven's notation for the tricapped trigonal prism of symmetry $\mathrm{D}_{3 \mathrm{~h}}$ and anisotropic $g$ factors $\left(g_{x}, g_{y}\right.$ and $\left.g_{z}\right)$ as reported in Tables S1 (in ESI). These CF and g-factor parameters give a good simulation of the field dependence of magnetization, especially at low fields (Figure S1).

For $\mathrm{GdL}_{3}$ the $\chi \mathrm{T}$ value is $8.34 \mathrm{emu} \mathrm{K} \mathrm{mol}{ }^{-1}$ at $300 \mathrm{~K}$ and it is almost constant during cooling down to $20 \mathrm{~K}$ then decrease slightly to reach $7.38 \mathrm{emu} \mathrm{K} \mathrm{mol}{ }^{-1}$ at $2 \mathrm{~K}$. As well for the magnetization, it is continuously increasing with the magnetic field to reach almost saturation $\left(6.69 \mu_{B}\right)$ at $5 T$. These behavior are in agreement with one $\mathrm{Gd}^{3+}\left(\mathrm{S}=7 / 2, \chi \mathrm{T}=7.375 \mathrm{emu} \mathrm{K} \mathrm{mol}^{-1}\right.$ 1. ${ }^{69}$ and accordingly is well fitted with g-factor $=2.04$ and an almost non-significant intermolecular antiferromagnetic interaction $\mathrm{ZJ}=-0.002( \pm 1) \mathrm{cm}^{-1}$.

2.7 EPR spectrocopy 
The neutral complexes $\mathrm{EuL}_{3}, \mathbf{G d L}_{3}$ and $\mathrm{YbL}_{3}$ contain a paramagnetic lanthanide ion and therefore were subjected to an EPR analysis. Conversely, complex $\mathrm{LuL}_{3}$ can be used as a diamagnetic reference whereby only the oxidised compounds (cation and dication) give rise to paramagnetic species.
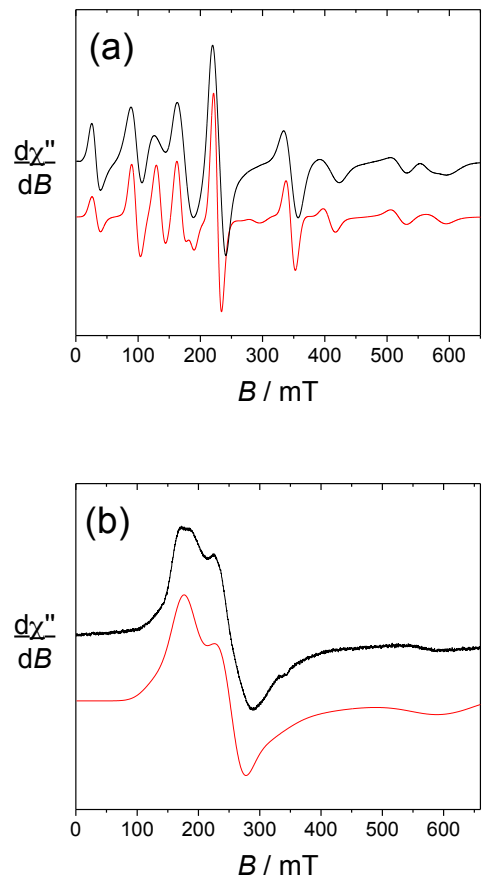

Figure 6. Powder EPR spectrum of (a) $\mathrm{GdL}_{3}$ and (b) $\mathrm{YbL}_{3}$. Black lines: Experimental

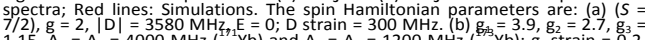

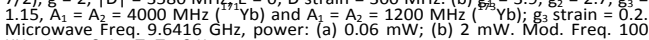
Hz; Amp. $0.4 \mathrm{mT}$. $T=9 \mathrm{~K}$.

The complex EuL $\mathrm{L}_{3}$ proved to be difficult to observe in the temperature range $100-10 \mathrm{~K}$. This result is not unexpected due to the combined effects of the fast relaxation of the lanthanide ion, and its odd multiplicity $(S=3)$. Conversely, the $\mathrm{Gd}^{\mathrm{III}}$ ion could be readily detected by EPR (Figure 6a) because the $\mathrm{f}$ shell is half-filled $(S=7 / 2)$ and hence the total momentum $J$ and the spin momentum $S$ are equal ("S-state" metal ion). Consequently the energy gap between the ground and excited multiplets is large, resulting in a slow relaxation and allowing the observation of spectra even up to room temperature. The powder spectrum of the corresponding $\mathrm{GdL}_{3}$ species displays at least nine lines in the spectral window 1-660 mT (Figure 6a). The broad distribution of resonances suggests that the zero field splitting (ZFS) is operating and that the ZFS parameter $D$ is larger than the X-Band quantum. The $\mathrm{D}$ value in $\mathrm{Gd}$ complexes is proved to be very sensitive to the geometry and can span over a broad range ${ }^{70-72}$ Unfortunately, the spectra are often broad ${ }^{72}$ due to a distribution of the ZFS parameters, which needs to be correctly modelled. The unique resolution of the spectrum of $\mathbf{G d L}_{3}$ allows for the direct determination of the $D$ and $E$ parameters with an unusual precision for a $\mathrm{Gd}^{\prime \prime \prime}$ complex. We obtained a satisfactory simulation by considering an isotropic $g$ value of 2.00 and an axial (or quasi axial within the accuracy of the determination of E) ZFS with $|D|=3580 \pm 400$ $\mathrm{MHz}$. The fact that the ZFS is nearly axial is consistent with the symmetry of the complex. On the other hand the $|D|$ value is larger than those obtained for macrocyclic chelates, which range between 570 and $1800 \mathrm{MHz}$ (with the lowest and highest values for [Gd(DOTA) $\left.\left(\mathrm{H}_{2} \mathrm{O}\right)\right]^{-}$and iodo-Gd-PCTA-[12]), 71,72 respectively). It is also larger than those reported for acyclic complexes, which span over a shorter range (1440-1710 $\mathrm{MHz}$ ), with the smallest value being obtained for $\left.\left[\mathrm{Gd}(\mathrm{DTPA})\left(\mathrm{H}_{2} \mathrm{O}\right)\right]^{2-}\right)^{71}$
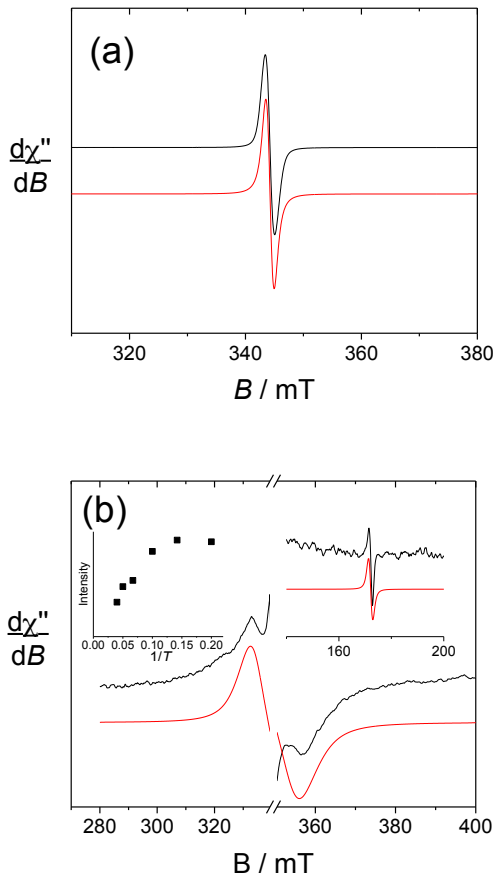

Figure 7. Powder EPR spectrum of (a) $\mathrm{LuL}_{3}{ }^{+}$and (b) $\mathrm{LuL}_{3}{ }^{2+}$. Black lines: are: (a) $(S=1 / 2), g_{i s o}=2.000$. (b) $(S=1)$, gisis $=1.997,|D|=260 \mathrm{MHZ} E=0$.

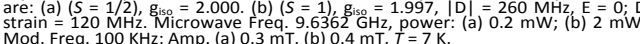

The $\mathrm{Yb}^{\prime \prime \prime}$ ion within $\mathrm{YbL}_{3}$ is a system with even multiplicity. The powder spectrum of this complex displays features in the 100$300 \mathrm{mT}$ region, as well as a broader line at higher field (Figure 
6b). The low field component is composed of two main lines as well as satellite shoulders of lower intensity. We fitted this spectrum by using the spin Hamiltonian parameters $\mathrm{g}_{1}=3.9, \mathrm{~g}_{2}$ $=2.7$ and $g_{3}=1.15$ for all the $\mathrm{Yb}$ isotopes. In order to account for the outermost lines we considered the ${ }^{171} \mathrm{Yb}$ isotope $(/ \mathrm{Yb}=$ $1 / 2$, natural abundance $14 \%$ ) with HFC constants $A_{Y b}{ }^{1}=A_{Y b}{ }^{2}=$ $4000 \mathrm{MHz}$. We estimated the HFC constants with the ${ }^{173} \mathrm{Yb}$ isotope $\left(I_{Y b}=5 / 2\right.$, natural abundance $\left.16 \%\right)$ to $A_{Y b}{ }^{1}=A_{Y b}{ }^{2}=$ $1200 \mathrm{MHz}$ from the ratio of the gyromagnetic ratio ${ }^{173} \mathrm{Yb} /{ }^{171} \mathrm{Yb}$. Having characterized the neutral precursors we next examined the oxidized species. The spectrum of the cation $\mathrm{EuL}_{3}{ }^{+}$consists of an unresolved and intense resonance centered at $\mathrm{g}=1.955$ (peak-to-peak line width of $9.5 \mathrm{mT}$ ). It is the result of a halfinteger spin system that forms upon one-electron oxidation of the neutral $\mathrm{EuL}_{3}$ and likely arises from the transition within the $1 / 2$ Kramers'doublet. The oxidized species $\mathrm{GdL}_{3}{ }^{+}$is an integer spin system, which proved to be difficult to observe over the investigated temperature range $(T=7-25 \mathrm{~K})$.

For the ytterbium complexes both the monocation and the dication were found to be essentially EPR-silent. While this might be expected for monoradical complexes of ytterbium this is rather surprising for $\mathrm{YbL}_{3}{ }^{2+}$, which is a half-integer spin system. Possible explanations are strong Yb-radical interactions in the diradical system and further line broadening or dimerization equilibria in solution. Due to the lack of specific signature it was not possible to go further in the EPR analysis for this complex.

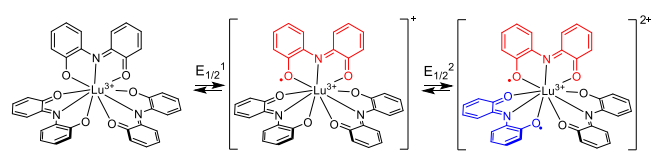

Scheme 2. Successive oxidation processes in $\mathrm{LuL}_{3}$. The $t$-Bu groups have been
omitted for clarity.

The oxidized complex that is the easiest to characterize by EPR spectroscopy is $\mathrm{LuL}_{3}{ }^{+}$. Its spectrum (Figure 7a) is typical of an ( $S$ $=1 / 2$ ) radical system, with a single resonance at $g=2.000$ (peakto-peak linewidth of $1.7 \mathrm{mT}$ ). The $\mathrm{g}$ value is close to that of free electron, as expected for organic radicals, while no HFC could be resolved, presumably as a result of the substantial linewidth. The spectrum of the dication $\mathrm{LuL}_{3}{ }^{2+}$ consists of two overlapped signals (Figure 7b). One is similar to $\mathrm{LuL}_{3}{ }^{+}$, suggesting that the monocation is present as contaminant in the solution. By analysis of the intensity we estimate the amount of $\mathrm{LuL}_{3}{ }^{+}$to $30-40 \%$ with respect to the total expected spin concentration, which is consistent with rotating disc electrode voltammetry. Satellite lines, which correspond to a triplet system, are observed around the band at $g=2.000$. This assumption is further confirmed by the presence of a weak half-field "forbidden" $\Delta \mathrm{M}_{\mathrm{S}}=2$ transition at $175 \mathrm{mT}$ (insert in Fig. 7b). The triplet resonances are assigned to $\mathrm{LuL}_{3}{ }^{2+}$. They could be satisfactorily simulated by using the following spin Hamiltonian parameters: $g=1.997,|D|=260 \mathrm{MHz}, \mathrm{E}=0$. Both the $g$ value and the ZFS parameter $D$ are consistent with a bis(radical) nature of $\mathrm{LuL}_{\mathbf{3}}{ }^{2+}$. Thus they confirm that the oxidation process involves two successive one-electron transfers on distinct ligand molecules according to Scheme 2. The ID| value is slightly smaller than those reported for octahedral zinc bis(phenoxyl) radical systems based on Schiff bases $(360-540 \mathrm{MHz})^{73}$ and gallium bis(iminosemiquinone) complexes $(617-672 \mathrm{MHz})^{74}$. This suggests an increased spatial separation of the radicals in $\mathrm{LuL}_{3}{ }^{2+}$, in agreement with larger coordination bond distances in the lanthanide series, in addition to changes in the orientation of the radical moieties. By using the dot dipole approximation the interspin distance is calculated at ca. 7.5 ̊. This value compares with the distances between the centroids of the aromatic rings of distinct ligand molecules (in the 6.5-8.6 ̊̊ range depending on the considered aromatic ring). We further investigated the temperature dependence of the triplet signal over the $5-25 \mathrm{~K}$ temperature range. The plot of $\mathrm{I}$ as a function of $1 / T$ shows a saturation behaviour at ca. $1 / \mathrm{T}=0.2$, indicative of weak antiferromagnetic interactions between the two ligand-radical spins. The fit of the curve IT as a function of T (Figure 6) gives an exchange coupling constant $J=-3 \pm 1 \mathrm{~cm}^{-1}$. The $J$ value is smaller than that determined for zinc(II) bis(phenoxyl) radical systems, disclosing weaker magnetic coupling in our tris(ligand) system. Further comparison is difficult since the nature of the exchange depends strongly on the orientation of the radical planes and hence the geometry of the coordination sphere.

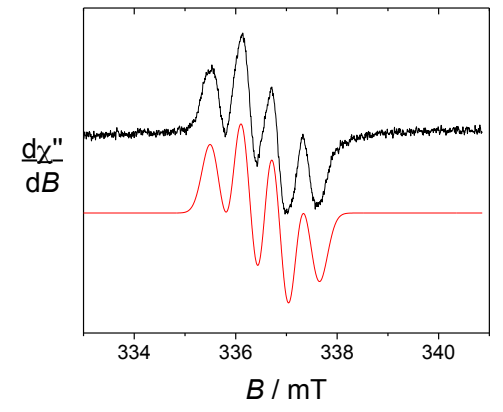

Figure 8. Solution EPR spectrum of $\mathrm{LuL}_{2}{ }^{-}$in $0.5 \mathrm{mM} \mathrm{CH}_{2} \mathrm{Cl}_{2}$ solution containing 0.1 Hamiltonian parameters $(S=1 / 2)$, , $p_{\text {iso }}=2.002, A_{N}=16 \mathrm{MHz}, A_{H}=16 \mathrm{MHZ}, A_{H}=6$
Hen $\mathrm{MHz}$ Microw
$\mathrm{mT} . \mathrm{T}=293 \mathrm{~K}$.

Finally we examined the anionic complexes, which were generated electrochemically in the glove box. All the complexes exhibit a similar resonance at $\mathrm{g}=2.00$ that is reminiscent of monosemiquinone radical systems. ${ }^{75}$ For the lutetium complex LuL $_{3}{ }^{-}$, which is the only genuine $(S=1 / 2)$ system of the series, we additionally recorded the spectrum at $293 \mathrm{~K}$. Under isotropic regime the spectrum shows a welldefined four-line pattern. It was simulated by considering the hyperfine interaction with one ${ }^{14} \mathrm{~N}$ nucleus $(16 \mathrm{MHz})$, and two inequivalent ${ }^{1} \mathrm{H}$ nuclei (14 and $6 \mathrm{MHz}$ ), which are assigned to 
the nitrogen and the two aromatic hydrogens of the semiquinone, respectively. ${ }^{51,76}$ The fact that there is only one strongly coupled ${ }^{1} \mathrm{H}$ nucleus indicates that the radical tends to localize on one ring, within a single ligand moiety.

\section{Conclusions}

In summary we have prepared lanthanide complexes of the redox non-innocent N,N'-bis(2-hydroxy-di-3,5-tertbutylphenyl)amine pincer ligand. The metal is ninecoordinated, surrounded by three ligand moieties under their monoanionic (Cat-N-BQ) form. The complexes demonstrate three one-electron oxidations, which are assigned to the successive oxidation of the three ligands, as well as a reduction event that is also assigned to a ligand-centered redox process. The oxidized and reduced products contain semiquinone radical moieties, with distinct Vis-NIR features. The dication $\mathrm{LuL}_{3}{ }^{2+}$, which was formed with the diamagnetic lutetium ion, allowed for the determination of both the ZFS parameters and the exchange coupling constant $J_{v}$

\section{Experimental Section}

\subsection{Materials and methods}

All chemicals were of reagent grade and were used without purification. Lanthanide nitrate salts were purchased from Aldrich and titrated for metal content before use, in the presence of EDTA and xylene orange. High resolution mass spectra were recorded on a Waters Xevo G2-S QTof apparatus. The UV/Vis spectra were recorded on a Cary Varian 50 spectrophotometer equipped with a Hellma immersion probe (1.000 cm path length) or a Perkin Elmer Lambda 1050 spectrophotometer. NMR spectra were recorded on a Bruker AM $400\left({ }^{1} \mathrm{H}\right.$ at $\left.400 \mathrm{MHz}\right)$ spectrometer. Chemical shifts are quoted relative to tetramethylsilane (TMS). X-band EPR spectra were recorded on a Bruker EMX Plus spectrometer equipped with a Bruker Helium flow cryostat and a dual mode cavity. Cyclic voltammetry curves as well as differential pulse voltammetry curves were recorded using a CHI 620 potentiostat. The measurements were performed in $0.5 \mathrm{mM}$ $\mathrm{CH}_{2} \mathrm{Cl}_{2}$ solution containing $0.1 \mathrm{M}$ tetra- $n$-butyl ammonium perchlorate (TBAP) as supporting electrolyte. Experiments were performed in a standard three-electrode cell under argon atmosphere (glove box). A glassy carbon disc electrode (3 mm diameter), which was polished with $1 \mathrm{~mm}$ diamond paste, was used as the working electrode. The auxiliary electrode is a compartmentalized platinum wire, while an $\mathrm{Ag} / \mathrm{AgNO}_{3} 0.01 \mathrm{M}$ electrode was used as reference. The electrolysis was carried out at $233 \mathrm{~K}$ on a Biologic SP 300 potentiostat, by using a carbon foam working electrode.

Luminescence spectra of the lanthanide complexes were recorded using a modular Fluorolog FL3-22 spectrometer Horiba-Jobin Yvon-Spex equipped with a double grating excitation monochromator and an iHR320 imaging spectrometer. Hamamatsu R928P and Hamamatsu R5509 photomultipliers were used for visible and NIR measurements, respectively. All spectra were corrected for detection and optical spectral response (instrumental functions) of the spectrofluorimeters. Quartz capillaries $4 \mathrm{~mm}$ in diameter were used. For the acquisition of the excitation and emission spectra in the NIR, a long pass coloured filter was always used at 870 $\mathrm{nm}$ to block the signal of the $2 \mathrm{nd}$ harmonics.

The temperature dependence of the magnetic susceptibility was measured in the temperature range $2-350 \mathrm{~K}$ in an applied magnetic field of $0.1 \mathrm{~T}$ using a SQUID magnetometer from Quantum Design model MPMS-XL. Magnetization versus magnetic field (0-0.5 T) was measured at $2 \mathrm{~K}$. All data were corrected for the contribution of the sample holder and diamagnetism of the samples estimated from Pascal's constants. ${ }^{77}$ The PHI software was used for the fitting of the experimental magnetic data. ${ }^{63}$

\subsection{Synthesis}

The ligand was synthesised using literature procedures. ${ }^{45,46}$ The complexes were synthesised via a template synthesis. In a typical experiment a solution of 3,5-di-tert-butylcatechol ( $0.099 \mathrm{~g}, 0.44 \mathrm{mmol}, 6 \mathrm{eq}$ ) in $10 \mathrm{~mL}$ of $\mathrm{EtOH}$ was added to a solution of $\mathrm{Ln}\left(\mathrm{NO}_{3}\right)_{3} . \mathrm{xH}_{2} \mathrm{O}(0.073 \mathrm{mmol}, 1$ equiv.) in $\mathrm{EtOH}$ (10 $\mathrm{mL})$. Concentrated ammonia $(2 \mathrm{ml})$ was added, forming a deep blue solution. A dark precipitate was formed which was collected by filtration. Each of the complexes was prepared and isolated under crystalline form following the same procedure.

GdL $_{3}$. Yield : $94 \%$. HR-MS (Q-TOF): m/z, 1425.8509; Calculated for $\mathrm{C}_{84} \mathrm{H}_{121} \mathrm{~N}_{3} \mathrm{O}_{6} \mathrm{Gd}$ : 1425.8513 . Elemental analysis: $\mathrm{C}, 70.77 ; \mathrm{H}$, 8.17; N, 3.01; Calculated for $\mathrm{C}_{84} \mathrm{H}_{120} \mathrm{~N}_{3} \mathrm{O}_{6} \mathrm{Gd} \bullet 0.3 \mathrm{CH}_{2} \mathrm{Cl}_{2}$ : C, 69.69; H, 8.37; N, 2.89

EuL $_{3}$. Yield : $67 \% .{ }^{1} \mathrm{H} \mathrm{NMR}\left(400 \mathrm{MHz}, \mathrm{CDCl}_{3}\right) \delta=5.13(\mathrm{~s}), 4.89$ (s), 2.78 (s), 1.65 (s), 1.36 (s), 0.83 (s). HR-MS (Q-TOF): m/z, 1420.8469; Calculated for $\mathrm{C}_{84} \mathrm{H}_{121} \mathrm{~N}_{3} \mathrm{O}_{6}$ Eu: 1420.8462 . Elemental analysis: C, 71.17; H, 8.96; N, 3.31; Calculated for $\mathrm{C}_{84} \mathrm{H}_{120} \mathrm{~N}_{3} \mathrm{O}_{6} \mathrm{Eu}: \mathrm{C}, 71.04 ; \mathrm{H}, 8.53 ; \mathrm{N}, 2.96$

$\mathrm{YbL}_{3}$. Yield : $86 \%$. ${ }^{1} \mathrm{H}$ NMR $\left(400 \mathrm{MHz}, \mathrm{CDCl}_{3}\right) \delta=7.85$ (s), 5.79 (s), $2.05(\mathrm{~s} \mathrm{br}), 1.53-1.24(\mathrm{~m}), 0.46(\mathrm{~s}), 0.08(\mathrm{~s}) . \mathrm{HR}-\mathrm{MS}$ (Q-TOF): $\mathrm{m} / \mathrm{z}, 1441.8674$; Calculated for $\mathrm{C}_{84} \mathrm{H}_{121} \mathrm{~N}_{3} \mathrm{O}_{6} \mathrm{Yb}$ : 1441.8655 Elemental analysis: $\mathrm{C}, 64.14 ; \mathrm{H}: 7.97 ; \mathrm{N} ; 2.72$; Calculated for $\mathrm{C}_{84} \mathrm{H}_{121} \mathrm{~N}_{3} \mathrm{O}_{6} \mathrm{Eu}: \mathrm{C}, 64.16 ; \mathrm{H}, 7.68 ; \mathrm{N}, 2.64$.

LuL . Yield : $58 \% .{ }^{1} \mathrm{H}$ NMR $\left(400 \mathrm{MHz}, \mathrm{CDCl}_{3}\right) \delta=7.09(\mathrm{~s}, 6 \mathrm{H})$ 7.06 (s, 6H), 1.24 (s, 54H), 0.95 (s, 54H). HR-MS (Q-TOF): m/z, 1442.8652; Calculated for for $\mathrm{C}_{84} \mathrm{H}_{121} \mathrm{~N}_{3} \mathrm{O}_{6} \mathrm{Lu}$ 1442.8658. Elemental analysis: $\mathrm{C}, 64.73 ; \mathrm{H}, 8.32 ; \mathrm{N}, 2.67$. Calculated for $\mathrm{C}_{85} \mathrm{H}_{128} \mathrm{~N}_{3} \mathrm{O}_{9} \mathrm{Cl}_{2} \mathrm{Lu} \bullet \mathrm{CH}_{2} \mathrm{Cl}_{2} \bullet 3 \mathrm{H}_{2} \mathrm{O}: \mathrm{C}, 64.53 ; \mathrm{H}$, 8.17; N, 2.66.

4.3 X-Ray diffraction. Single crystals were coated with perfluoropolyether, picked up with nylon loops and mounted in the nitrogen cold stream of the diffractometer. Mo-Ka radiation ( $\lambda=0.71073 \AA$ ) from a Mo-target rotating-anode $X$ ray source equipped with INCOATEC Helios mirror optics was used. Final cell constants were obtained from least squares fits of several thousand strong reflections. Intensity data were corrected for absorption using intensities of redundant 
reflections with the program SADABS. The structures were solved by Patterson methods and subsequent difference Fourier techniques. The OLEX software was used for the refinement. $^{78}$ All non-hydrogen atoms were anisotropically refined and hydrogen atoms were placed at calculated positions and refined as riding atoms with isotropic displacement parameters. CCDC-1991222-1991223 contain the crystallographic data for $\mathrm{LnL}_{3}(\mathrm{Ln}=\mathrm{Gd}$, Eu and $\mathrm{Lu}$ ); these data can be obtained free of charge via http://www.ccdc.cam.ac.uk/conts/retrieving.html. The SHAPE software was used to determine the metal center coordination geometry by continuous shape measurement. ${ }^{61}$

\section{Acknowledgements}

This work is supported by the French National Research Agency in the framework of the "Investissements d'avenir" program (ANR-15-IDEX-02), Labex ARCANE and CBH-EURGS (ANR-17-EURE-0003) and the French National Agency for Research (Co-Lantha/ANR-17-CE07-0034) for financial support. The NanoBio-ICMG platforms (FR 2607) are acknowledged for their support.

\section{Notes and references}

1. P. J. Chirik and K. Wieghardt, Science, 2010, 327, 794795.

2. See the special issue on "Cooperative and Redox Noninnocent Ligands in Directing Organometallic Reactivity", Eur. J. Inorg. Chem., 2012, 340-580.

3. O. R. Luca and R. H. Crabtree, Chemical Society Reviews, 2013, 42, 1440-1459.

4. D. L. J. Broere, R. Plessius and J. I. van der Vlugt, Chemical Society Reviews, 2015, 44, 6886-6915.

5. See the special forum issue on "Applications of Metal Complexes with Ligand-Centered Radicals", Inorg. Chem., 2018, 57, 9577-10480.

6. A. Vlcek, Coordination Chemistry Reviews, 2010, 254, 1357.

7. B. d. Bruin, P. Gualco and N. D. Paul, in Ligand Design in Metal Chemistry, ed. M. S. a. R. J. Lundgren, 2016, pp. 176204

8. F. Thomas, in Stable Radicals: Fundamentals and Applied Aspects of Odd-Electron Compounds, ed. R. G. Hicks, John Wiley and Sons, Chichester, 2010, pp. 281-316.

9. C. T. Lyons and T. D. P. Stack, Coordination Chemistry Reviews, 2013, 257, 528-540.

10. Y. Shimazaki, Advances in Materials Physics and Chemistry, 2013, 3, 12.

11. F. Thomas, Dalton Transactions, 2016, 45, 10866.

12. N. Ito, S. E. V. Phillips, C. Stevens, Z. B. Ogel, M. J. McPherson, J. N. Keen, K. D. S. Yadav and P. F. Knowles, Nature, 1991, 350, 87-90.
13. M. M. Whittaker, C. A. Ekberg, J. Peterson, M. S. Sendova, E. P. Day and J. W. Whittaker, Journal of Molecular Catalysis B: Enzymatic, 2000, 8, 3-15.

14. J. W. Whittaker, Archives of Biochemistry and Biophysics, 2005, 433, 227-239.

15. Amanda K. Chaplin, Marloes L. C. Petrus, G. Mangiameli, Michael A. Hough, Dimitri A. Svistunenko, P. Nicholls, D. Claessen, E. Vijgenboom and Jonathan A. R. Worrall, Biochemical Journal, 2015, 469, 433-444.

16. P. R. Ortiz de Montellano, Chem. Rev., 2010, 110, 932-948.

17. P. R. Ortiz de Montellano, in Biocatalysis Based on Heme Peroxidases, Springer-Verlag, Berlin, 2010, p. 79.

18. J. Rittle and M. T. Green, Science, 2010, 330, 933-937.

19. F. Thomas, European Journal of Inorganic Chemistry, 2007, 2379-2404.

20. V. Lyaskovskyy and B. de Bruin, ACS Catalysis, 2012, 2, 270-279.

21. K. T. Sylvester and P. J. Chirik, Journal of the American Chemical Society, 2009, 131, 8772-8774.

22. V. A. Schmidt, J. M. Hoyt, G. W. Margulieux and P. J. Chirik, Journal of the American Chemical Society, 2015, 137, 7903-7914.

23. A. L. Smith, K. I. Hardcastle and J. D. Soper, Journal of the American Chemical Society, 2010, 132, 14358-14360.

24. D. L. J. Broere, N. P. van Leest, B. de Bruin, M. A Siegler and J. I. van der Vlugt, Inorganic Chemistry, 2016, 55, 8603-8611.

25. J. M. Hoyt, V. A. Schmidt, A. M. Tondreau and P. J. Chirik, Science, 2015, 349, 960-963.

26. D. Parker, R. A. Poole and F. Kielar, 2006, WO2008007089.

27. B. Song, G. Wang, M. Tan and J. Yuan, Journal of the American Chemical Society, 2006, 128, 13442-13450.

28. G.-L. Law, R. Pal, L. O. Palsson, D. Parker and K.-L. Wong, Chemical Communications, 2009, 7321-7323.

29. A. R. Lippert, T. Gschneidtner and C. J. Chang, Chemical Communications, 2010, 46, 7510-7512.

30. J. Hong, Y. Zhuang, X. Ji and X. Guo, Analyst, 2011, 136, 2464-2470.

31. M. Tropiano, N. L. Kilah, M. Morten, H. Rahman, J. J. Davis, P. D. Beer and S. Faulkner, Journal of the American Chemical Society, 2011, 133, 11847-11849.

32. B. K. McMahon and T. Gunnlaugsson, Journal of the American Chemical Society, 2012, 134, 10725-10728.

33. Y. Xiao, Z. Ye, G. Wang and J. Yuan, Inorganic Chemistry, 2012, 51, 2940-2946.

34. K. L. Peterson, M. J. Margherio, P. Doan, K. T. Wilke and V. C. Pierre, Inorganic Chemistry, 2013, 52, 9390-9398. 35. M. Abdesselem, R. Ramodiharilafy, L. Devys, T. Gacoin, A. Alexandrou and C. I. Bouzigues, Nanoscale, 2017 9, 656-665.

36. A. J. Amoroso and S. J. A. Pope, Chemical Society Reviews, 2015, 44, 4723-4742.

37. J. K. Molloy, O. Jarjayes, C. Philouze, L. Fedele, D. Imbert and F. Thomas, Chemical Communications, 2017, 53, 605-608. 
38. J. K. Molloy, L. Fedele, O. Jarjayes, C. Philouze, D. Imbert and F. Thomas, Inorganica Chimica Acta, 2018, 483, 609-617.

39. J. K. Molloy, C. Philouze, L. Fedele, D. Imbert, O. Jarjayes and F. Thomas, Dalton Transactions, 2018, 47, 10742-10751.

40. K. S. Min, T. Weyhermüller, E. Bothe and K. Wieghardt, Inorganic Chemistry, 2004, 43, 2922-2931.

41. S. Kokatam, T. Weyhermüller, E. Bothe, P. Chaudhuri and K. Wieghardt, Inorganic Chemistry, 2005, 44, 37093717.

42. A. I. Poddel'sky, V. K. Cherkasov and G. A. Abakumov Coordination Chemistry Reviews, 2009, 253, 291-324.

43. J. Jacquet, E. Salanouve, M. Orio, H. Vezin, S. Blanchard, E. Derat, M. Desage-El Murr and L. Fensterbank, Chemical Communications, 2014, 50, 10394-10397.

44. J. Bendix and K. M. Clark, Angewandte Chemie International Edition, 2016, 55, 2748-2752.

45. S. K. Larsen and C. G. Pierpont, Journal of the American Chemical Society, 1988, 110, 1827-1832.

46. C. L. Simpson, S. R. Boone and C. G. Pierpont, Inorganic Chemistry, 1989, 28, 4379-4385.

47. B. G. Maiya, Y. Deng and K. M. Kadish, Journal of the Chemical Society, Dalton Transactions, 1990, 3571-3576.

48. C. G. Pierpont and C. W. Lange, in Progress in Inorganic Chemistry, 1994, pp. 331-442.

49. P. Chaudhuri, M. Hess, T. Weyhermüller and K. Wieghardt, Angewandte Chemie International Edition, 1999, 38, 1095-1098.

50. D. Ruiz-Molina, J. Veciana, K. Wurst, D. N. Hendrickson and C. Rovira, Inorganic Chemistry, 2000, 39, 617-619.

51. P. Chaudhuri, M. Hess, K. Hildenbrand, E. Bill, T. Weyhermüller and K. Wieghardt, Inorganic Chemistry, 1999, 38, 2781-2790.

52. A. Piskunov, I. Smolyaninov and O.Yu.Sukhoshkina, Russian Journal of General Chemistry, 2010, 80, 790-799.

53. G. Szigethy and A. F. Heyduk, Dalton Transactions, 2012, 41, 8144-8152.

54. G. Szigethy, D. W. Shaffer and A. F. Heyduk, Inorganic Chemistry, 2012, 51, 12606-12618.

55. J. L. Wong, R. H. Sánchez, J. G. Logan, R. A. Zarkesh, J. W. Ziller and A. F. Heyduk, Chem. Sci., 2013, 4, 1906-1910. 56. S. N. Lyubchenko, V. A. Kogan and L. P. Olekhnovich, Russian Journal of Coordination Chemistry, 1996, 22, 534540.

57. G. Speier, J. Csihony, A. M. Whalen and C. G. Pierpont, Inorganic Chemistry, 1996, 35, 3519-3524.

58. N. G. Furmanova, S. N. Lyubchenko, V. Kogan and L. P. Olekhnovich, Crystallography Reports, 2000, 45, 439-443. 59. A. A. Maleev, O. Y. Trofimova, A. P. Pushkarev, N. V. Somov, V. V. Travkin, G. L. Pakhomov, A. V. Piskunov and M. N. Bochkarev, Nanotechnologies in Russia, 2015, 10, 613620.

60. C. Camacho-Camacho, G. Merino, F. J. MartínezMartínez, H. Nöth and R. Contreras, European Journal of Inorganic Chemistry, 1999, 1999, 1021-1027.
61. M. Llunell, D. Casanova, J. Cirera, P. Alemany and S. Alvarez, Journal, 2013.

62. I. L. Fedushkin, D. S. Yambulatov, A. A. Skatova, E. V. Baranov, S. Demeshko, A. S. Bogomyakov, V. I. Ovcharenko and E. M. Zueva, Inorganic Chemistry, 2017, 56, 9825-9833. 63. N. F. Chilton, R. P. Anderson, L. D. Turner, A. Soncini and K. S. Murray, Journal of Computational Chemistry, 2013, 34, 1164-1175.

64. S. V. Larionov, Y. A. Bryleva, L. A. Glinskaya, V. F. Plyusnin, A. S. Kupryakov, A. M. Agafontsev, A. V. Tkachev, A. S. Bogomyakov, D. A. Piryazev and I. V. Korolkov, Dalton Transactions, 2017, 46, 11440-11450.

65. S. Shintoyo, T. Fujinami, N. Matsumoto, M. Tsuchimoto, M. Weselski, A. Bienko and J. Mrozinski, Polyhedron, 2015, 91, 28-34.

66. O. Kahn, Molecular Magnetism, VCH, New York, 1993.

67. N. Karayianis, Journal of Chemical Physics, 1970, 53, 2460-2469.

68. F. Guegan, J. Jung, B. Le Guennic, F. Riobe, O. Maury, B. Gillon, J. F. Jacquot, Y. Guyot, C. Morell and D. Luneau, Inorganic Chemistry Frontiers, 2019, 6, 3152-3157.

69. A. Lannes and D. Luneau, Inorganic Chemistry, 2015, 54, 6736-6743.

70. A. Lasoroski, R. Vuilleumier and R. Pollet, The Journal of Chemical Physics, 2014, 141, 014201.

71. M. Benmelouka, J. Van Tol, A. Borel, M. Port, L. Helm, L. C. Brunel and A. E. Merbach, Journal of the American Chemical Society, 2006, 128, 7807-7816.

72. J. A. Clayton, K. Keller, M. Qi, J. Wegner, V. Koch, H. Hintz, A. Godt, S. Han, G. Jeschke, M. S. Sherwin and M. Yulikov, Physical Chemistry Chemical Physics, 2018, 20, 10470-10492.

73. M. Orio, C. Philouze, O. Jarjayes, F. Neese and F. Thomas, Inorganic Chemistry, 2010, 49, 646-658.

74. A. V. Piskunov, I. V. Ershova, A. S. Bogomyakov, A. G. Starikov, G. K. Fukin and V. K. Cherkasov, Inorganic Chemistry, 2015, 54, 6090-6099.

75. A. Dei, D. Gatteschi, J. Pécaut, S. Poussereau, L. Sorace and K. Vostrikova, Comptes Rendus de I' Academie des Sciences Serie Ilc: Chimie, 2001, 4, 135-141.

76. M. A. Brown, J. A. Castro, B. R. McGarvey and D. G. Tuck, Canadian Journal of Chemistry, 1999, 77, 502-510. 77. G. A. Bain and J. F. Berry, J. Chem. Edu., 2008, 85, 532-536

78. O. V. Dolomanov, L. J. Bourhis, R. J. Gildea, J. A. K. Howard and H. Puschmann, J. Appl. Cryst., 2009, 42, 339340. 